\title{
Long-term prognosis for neck-shoulder pain and disorders: a 14-year follow-up study
}

\author{
Emma Lise Thorlund Jakobsen, ${ }^{1}$ Karin Biering, ${ }^{1}$ Anette Kærgaard, ${ }^{1}$ Annett Dalbøge, ${ }^{1,2}$ \\ Johan Hviid Andersen ${ }^{1}$
}

- Additional material is published online only. To view please visit the journal online (http://dx.doi.org/10.1136/ oemed-2017-104422).

'Department of Occupational Medicine, Danish Ramazzini Centre, Regional Hospital West Jutland, University Research Clinic, Herning, Denmark ${ }^{2}$ Department of Occupational Medicine, Danish Ramazzini Centre, Aarhus University Hospital, Aarhus, Denmark

\section{Correspondence to} Ms. Emma Lise

Thorlund Jakobsen, Department of Occupational Medicine, Danish Ramazzini Centre Regional Hospital West Jutland - University Research Clinic, Gl. Landevej 61, 7400, Herning, Denmark;

emmalise.jakobsen@gmail.com

Received 7 March 2017 Revised 5 July 2017 Accepted 20 July 2017 Published Online First 23 August 2017
ABSTRACT
Objectives The long-term prognosis for neck-shoulder pain and disorders and the impact of shoulder exposure among former sewing machine operators were investigated in a 14-year follow-up study.

Methods Information on neck-shoulder pain and disorders was collected by questionnaire and clinical examination at baseline in 243 female sewing machine operators and by questionnaire 14 years later. During follow-up, information on comorbidity and job exposures was obtained from registers and by linking registerbased D-ISCO 88 codes with a job exposure matrix. Logistic regression analyses were performed to examine associations between neck-shoulder pain and disorders at baseline and neck-shoulder pain and physical functioning at follow-up.

Results We found an association between neckshoulder disorders at baseline and neck-shoulder pain at follow-up (OR 5.9;95\% Cl 1.9 to 17.7), and between neck-shoulder pain at baseline and neck-shoulder pain at follow-up (OR 8.2;95\% Cl 3.5 to 19.2). Associations between neck-shoulder disorders and pain at baseline and limited physical functioning at follow-up had ORs of $5.0(95 \% \mathrm{Cl} 1.5$ to 16.1$)$ and $2.2(95 \% \mathrm{Cl} 1.1$ to $4.6)$, respectively. In women still working in 2008 , the association between neck-shoulder pain in 1994 and in 2008 seemed to be stronger for those in jobs with high job shoulder exposure.

Conclusions The results suggest a long-term adverse prognosis for neck-shoulder pain. High job shoulder exposure can worsen this prognosis for those who continue working. This knowledge could influence the counselling given to similar workers and emphasises the need to prevent neck-shoulder pain.

\section{INTRODUCTION}

There is a high prevalence of pain and disorders of the shoulder and neck. Non-specific shoulder and neck pain has been found in $6.5 \%-12 \%$ of the general population. ${ }^{12}$ However, lower and higher prevalences have been reported, probably due to differences in study populations and case definitions, for example, ${ }^{34}$ some studies include findings from physical examination, while others use only patient-reported symptoms. Research on occupational mechanical risk factors has revealed increased neck-shoulder pain in jobs with mechanical exposures such as repetitive movements, high force, arm-elevation and hand-arm-vibration. ${ }^{4-6}$

The short-term prognosis for neck-shoulder pain and disorders has been quite well studied even

\section{What this paper adds}

- Neck-shoulder pain is very prevalent among sewing machine operators, and symptoms may last for several years, although some workers recover from the condition more quickly.

- Knowledge of the long-term prognosis of neckshoulder pain is limited.

- This study reveals an association between neck-shoulder pain and disorders at baseline and neck-shoulder pain 14 years later after employment in the textile industry has ceased.

- High occupational shoulder exposure worsened the prognosis for neck-shoulder pain in those who continued to work.

- These results highlight the importance of the prevention of neck-shoulder pain at work.

though the results are relatively heterogeneous. Some patients recover in the first few years, while others continue to report pain. ${ }^{3-9}$ The long-term prognosis for neck-shoulder pain and disorders is less well studied as only a few studies have more than 3 years of follow-up, ${ }^{10-15}$ and the populations and outcome measures used have been relatively heterogeneous. Prevention strategies, optimisation of treatment and counselling are required if pain and/or disorders persist for a decade or longer.

A previous study on neck-shoulder pain and disorders among 243 female sewing machine operators found a $34.7 \%$ prevalence of moderate/ severe self-reported neck-shoulder pain. A clinically verified neck-shoulder disorder (rotator cuff tendinitis and/or neck-shoulder pain with pressure tenderness), based on a combination of self-reported pain and a clinical examination, was found in $16.8 \%$ of the cohort. ${ }^{6}$ In a control group with varied non-repetitive work, approximately $11 \%$ had a neck-shoulder disorder. In a follow-up of this cohort 1-2 years later, 12 out of 28 (42.9\%) had recovered from their neck-shoulder disorder. ${ }^{6}$ The current study is a long-term follow-up of this group of sewing machine operators. In the late 1990s, most of the Danish textile industry was outsourced to other countries, and the plants where study participants worked closed down around 1996. No follow-up investigations on neck-shoulder pain were conducted in these workers after they had lost their jobs, despite the fact that the textile industry generates many compensation claims for neck-shoulder disorders. The prognosis for neck-shoulder pain 
is an important public health concern as it is related to physical limitations ${ }^{16} 17$ and can decrease participation in the labour market. ${ }^{18-20}$ Knowledge of this issue is valuable for the career guidance of such patients in clinical and occupational settings.

Findings on occupational exposure relating to the prognosis of neck-shoulder pain are not completely consistent. One systematic review on prognostic factors in patients with shoulder pain concluded that studies were inconclusive regarding the impact of physical workload on prognosis, ${ }^{21}$ while another review on prognostic factors for arm, shoulder and neck complaints also found studies to be inconclusive regarding ergonomic risk factors at work. ${ }^{8}$ A 6-year follow-up study of 149 sewing machine operators found that neck symptoms had disappeared in 29\% of those who had continued as sewing machine operators and in $57 \%$ of those who had obtained other employment. Similar results were found for shoulder symptoms. ${ }^{15}$

The aim of this study was to investigate the long-term prognosis for neck-shoulder pain and disorders in terms of neckshoulder pain and physical functioning 14 years after initial assessment in a group of female sewing machine operators. The women left the textile industry during follow-up, and we evaluated whether their symptoms had ceased or persisted, and studied the effects of occupational shoulder exposure while adjusting for age, comorbidity and the number of transitions between different income types.

\section{METHODS}

\section{Study design}

The study was a 14-year follow-up study of 243 female sewing machine operators. Baseline information on neck-shoulder pain and disorders was collected in 1994 in an earlier study. ${ }^{6}$ The sewing machine operators were a subgroup within a large Danish project initiated in 1994 (Project on Research and Intervention in Monotonous work, PRIM) to investigate the physical and psychological effects of monotonous, repetitive work. ${ }^{62-25}$ The women were recruited from three Danish textile companies and were included if they had no inflammatory rheumatic disorders or trauma-induced disorders. Of 259 sewing machine operators invited, 243 agreed to participate. They filled in a questionnaire on current musculoskeletal pain and demographic details and underwent a standardised clinical examination of the neck, shoulders and arms. The information used in this study was collected from a follow-up questionnaire on neck-shoulder pain and physical functioning administered in 2008. Questionnaire data from a short-term follow-up investigation in 1995$1997^{6}$ are included in our analysis of pain fluctuation. In 1994 , all participants worked as sewing machine operators but lost their jobs due to outsourcing around 1996.

\section{Baseline: neck-shoulder pain and disorders in 1994}

We wanted to study the prognosis for neck-shoulder pain and disorders identified in 1994. The questionnaire on neckshoulder pain has been described previously ${ }^{6}$ and was a modified form of a questionnaire developed by Von Korff et al. ${ }^{26}$ It comprised a set of four questions for each of eight body regions; the results for the neck, right shoulder and left shoulder were used in this study. The four questions asked for symptoms during the last 3 months: (1) worst complaints, (2) average complaints, (3) reduced activity due to complaint, and (4) worst complaint during the last 7 days. The participants marked the severity of complaints on a $0-9$ scale, with 0 points meaning no complaints, and 9 points the worst possible pain. A total score of self-reported complaints for all three anatomical regions was calculated, giving a range of scores from 0 to 108 . Similar to the previous studies in this cohort, ${ }^{6}$ this combined score was dichotomised into $<24$ points for cases of non/mild pain and $\geq 24$ points for cases of moderate/severe pain.

The clinical examinations were conducted by trained physicians and included a test for signs of subacromial impingement syndrome, ${ }^{27}$ resisted abduction, and palpation for tenderness. Cases of clinically verified neck-shoulder disorders (ie, rotator cuff tendinitis and neck-shoulder pain with pressure tenderness) were identified from a combination of findings from clinical examination and the complaint score. Those conducting the clinical examination were blinded for complaint scores. In this paper, neck-shoulder pain refers to self-reported neck-shoulder pain, while neck-shoulder disorder refers to clinically verified neck-shoulder disorder. For analyses on pain in the neck, right shoulder and left shoulder, we used a cut-off of $\geq 12$ points for cases, as this was used in the previous study. ${ }^{6}$

\section{Outcome: neck-shoulder pain and physical functioning in 2008}

In 2008, a questionnaire was posted to the former sewing machine operators. It included the same questions on musculoskeletal pain used in the three first data collections from 1994 to 1997 and an additional 10 questions on physical functioning from the SF-36. Each question on physical functioning had three possible responses: 'Yes, limited a lot' (0 points), 'Yes, limited a little' (50 points), and 'No, not limited at all' (100 points). The RAND 36-item Health Survey 1.0 instrument ${ }^{28}$ was used to calculate the score. According to this instrument, a missing value is left out, and the estimated score for that person is the average of the remaining and answered questions. If less than five questions were answered, we excluded the person from the analysis of physical functioning (six persons). The resulting average of the answers was dichotomised at 85 points (the median) for logistic regression analysis. We used this high level for dichotomization because the 10 items cover different kinds of physical functioning, and we wished to take all limitations in physical functioning into account.

Data from the 1995 and 1997 questionnaires were included so we could determine fluctuations in neck-shoulder pain. Due to a high number of non-responders, we decided to use only the 1997 questionnaire, with any data missing in that questionnaire replaced with data from the 1995 questionnaire, which resulted in an overall response rate of 88\% for 1995-1997.

\section{Other variables}

Comorbidity was defined by ICD-10 codes for diseases included in Charlson's Comorbidity Index, ${ }^{29}$ and was calculated using data from the Danish National Patient Registry on contacts with hospitals in 1994-2008. ${ }^{30}$ The participants were dichotomised on whether or not they had any comorbidity during 1994-2008. We used a recently developed job exposure matrix (The Shoulder JEM) ${ }^{5132}$ to estimate job shoulder exposure in 1994-2008. The JEM classifies 2042 occupational titles in the Danish version of the International Standard Classification of Occupations (D-ISCO 88) into 172 homogeneous shoulder exposure groups. Job exposure in the 172 groups was rated by five occupational health physicians and expressed as a total shoulder load variable, combining forceful shoulder exertions during a full workday, hours per day with upper-arm elevation $>90^{\circ}$, repetitive shoulder movements and hand-arm vibrations. ${ }^{531}$ For each year during follow-up, the total shoulder load was estimated by combining The Shoulder JEM with year-by-year D-ISCO 88 codes for each participant. D-ISCO 88 
codes and data on hours worked per week were obtained from the Employment Classification Module (ECM) at Statistics Denmark. For years with incomplete or missing D-ISCO 88 codes, shoulder load exposure was set as the mean of the other years. Using information on employment status from the ECM, we adjusted estimates for part-time work and replaced estimated exposure with zero for years outside the labour market. Yearly exposures were summed to obtain the cumulative exposure during the 14 years of follow-up. Total shoulder load had scores of between 0 and 10 for each year, giving a cumulative total shoulder load of 0-140 points, which was dichotomised at 30 points, close to the mean. This dichotomization was hence based on the distribution in the study cohort and allocated work as a sewing machine operator in the high-exposure group. Further details on The Shoulder JEM are available elsewhere. ${ }^{531} 32$

From the Danish DREAM database, ${ }^{33}$ we retrieved information on work status, health-related benefits and number of transitions between different income types in 1994-2008. This database contains weekly information on each person's transfer payments, which were grouped into five different types: (1) working, (2) education/leave-of-absence/maternity leave, (3) unemployment, (4) health-related benefits, and (5) voluntary early retirement/public retirement pension/death/emigration. The number of transitions between these income types was counted and used as a variable in the regression analysis as a proxy for unstable work participation. This covariate was included because a high number of transitions might indicate a psychosocial burden which could influence musculoskeletal pain. ${ }^{4}$ The number of transitions was divided into tertiles for the analyses. Finally, we obtained information on age from the baseline questionnaire. We used Danish civil registration numbers $(\mathrm{CPR})^{34}$ for extracting data for the study population from the registers.

\section{Statistical analyses}

The associations between neck-shoulder pain and disorders in 1994 and outcomes in 2008 were analysed using logistic regression analysis adjusting for comorbidity, ${ }^{35}$ number of transitions between different income types and age squared because associations between age and neck-shoulder pain have previously been found. ${ }^{36}$ We also performed analyses on the specific prognosis for the separate anatomical regions.

To investigate the effect of job shoulder exposure, we repeated the analysis of the prognosis for neck-shoulder pain, stratified on low versus high cumulative job exposure. There were too few cases for to make this analysis on neck-shoulder disorders. We repeated the analysis on the subgroup still working in 2008. Statistical analyses were performed with STATA 14.1 (StataCorp LP, College Station, Texas, USA).

\section{RESULTS}

\section{Responders and non-responders}

A flow chart is presented in figure 1, and descriptive data for the entire cohort in table 1 . There were no striking differences between responders and non-responders in 2008 in terms of age, prevalence of neck-shoulder pain and disorders in 1994, seniority in the textile industry or characteristics of working life during follow-up. Comorbidity seemed to be more pronounced among non-responders, who also tended to have lower cumulative job shoulder exposure scores.

\section{The course of neck-shoulder pain}

At baseline, 34.7\% (95\% CI 28.7 to 41.1 ) of the 243 participating women had moderate/severe neck-shoulder pain and $16.8 \%$
(95\% CI 12.3 to 22.2 ) had a clinically verified neck-shoulder disorder. At the 2008 follow-up, $49.0 \%$ (95\% CI 40.7 to 57.3 ) of the 149 responders had moderate/severe neck-shoulder pain. The median physical functioning score in 2008 was 85, with lower and upper quartiles of 70 and 95, respectively.

Five $(21.7 \%)$ of those with a clinically verified disorder and 11 $(22.0 \%)$ of those with self-reported neck-shoulder pain reported none/mild pain in 2008. Supplementary figure 1 shows the changes between pain status, that is, between moderate/severe and none/mild neck-shoulder pain in 1994, in either 1995 or 1997 , and in 2008. Only data from the participants with data at all three time points are included. The status of $51(40 \%)$ of the participants changed at least once, while the status of $77(60 \%)$ remained unchanged, of whom 25 had moderate/severe pain and $52 \mathrm{had}$ none/mild pain at each time point.

\section{Associations for neck-shoulder prognosis}

Table 2 shows results from the univariate and multivariate logistic regression analyses. The adjusted ORs between neckshoulder pain and disorders in 1994 and moderate/severe neckshoulder pain in 2008 were 5.9 (95\% CI 1.9 to 17.7 ) and 8.2 (95\% CI 3.5 to 19.2), respectively. Significant associations were also found between neck-shoulder pain and disorder in 1994 and low physical functioning in 2008 with ORs of 5.0 (95\% CI 1.5 to 16.1$)$ and $2.2(95 \%$ CI 1.1 to 4.6$)$, respectively.

For the separate anatomical regions, the adjusted OR for the association between neck-pain in 1994 and in 2008 was 3.4 (95\% CI 1.6 to 7.4). Correspondingly, for right and left shoulder pain, the ORs were 7.1 (95\% CI 2.8 to 18.1$)$ and $2.9(95 \%$ CI 1.3 to 6.5 ).

\section{Job shoulder exposure}

The mean cumulative job shoulder exposure during the 14 years of follow-up was 29.3 points (table 1 ) and had a normal distribution with SD 17.5 points and range $0-84.7$ points. Working as sewing machine operator from 1994 to 2008 would have accumulated 35.8 points of job exposure. For comparison, 14 years of slaughter house work would accumulate 109.7 points.

Estimates for neck-shoulder pain prognosis stratified on low and high job exposure are shown in table 3. For neck-shoulder pain in 2008, there was no significant difference between those with low versus high job exposure, although the group with low exposure had the highest OR of 12.0 (95\% CI 3.2 to 44.4) versus an OR of 9.1 (95\% CI 2.4 to 34.0) for the high-exposure-group. This result was reversed when the analysis was carried out only on those still working in 2008, so the group with low exposure had an OR of 11.5 (95\% CI 0.6 to 217.6) versus an OR of 20.8 (95\% CI 3.5 to 122.8 ) for the high-exposure group. The ORs for low physical functioning were very similar in the low- and high-exposure groups.

\section{DISCUSSION}

\section{Key results}

Only a few of the women with neck-shoulder pain or disorders in 1994 had recovered in 2008 even though they had all left their jobs in the original textile companies. Indeed, the prevalence of neck-shoulder pain had increased. After adjustment for potential confounders, both earlier neck-shoulder pain and clinically verified neck-shoulder disorders were associated with neckshoulder pain and limited physical functioning in 2008. Hence, neck-shoulder pain seemed to have a long-term adverse prognosis. High occupational shoulder exposure during follow-up may have worsened the prognosis in those still working in 2008. 
1994: 259 sewing machine operators from 3 companies were invited. Exclusion of inflammatory rheumatic disease and disorders caused by trauma

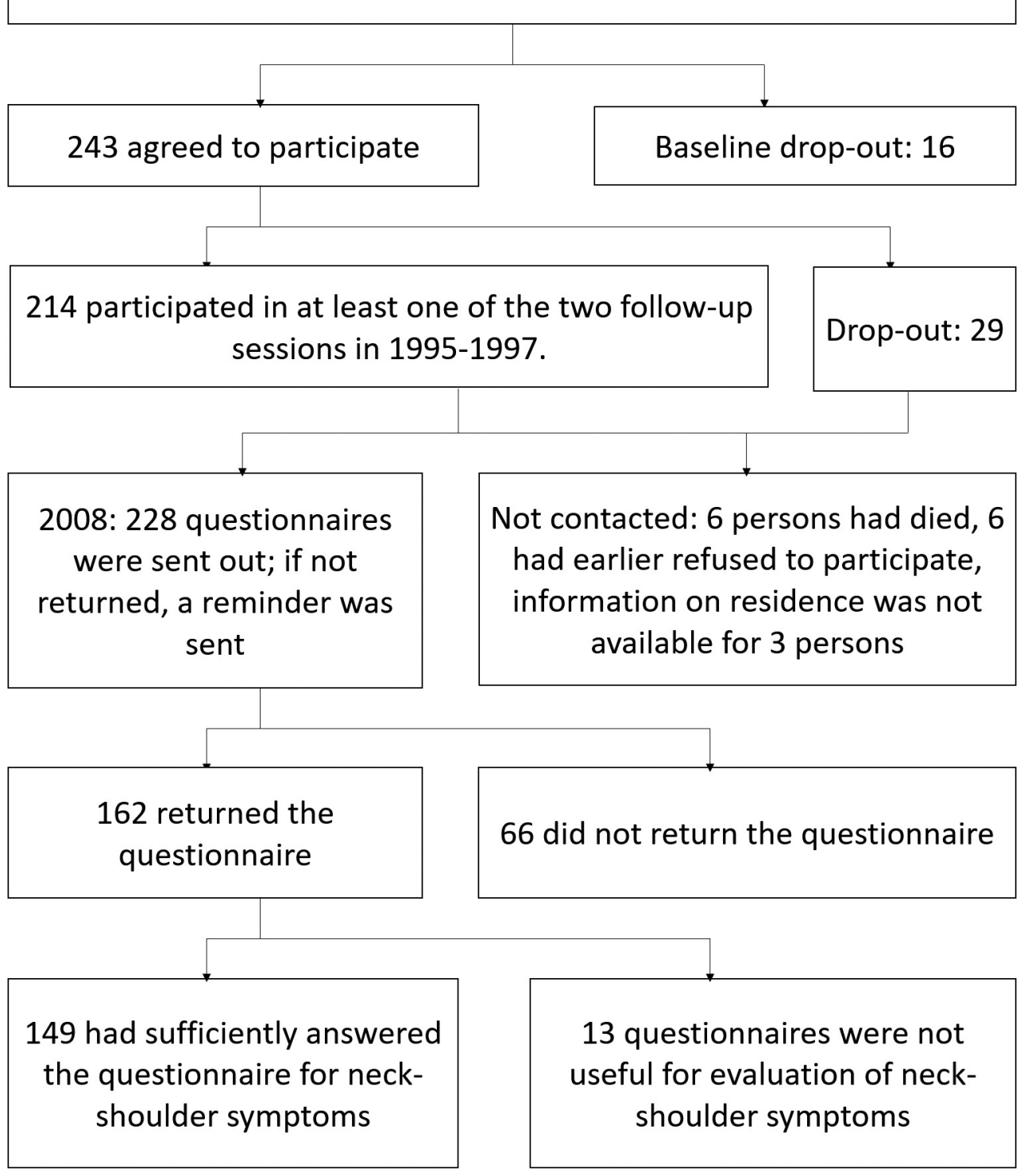

Figure 1 Flow chart of participation.

\section{Strengths and limitations}

The strengths of this follow-up study were the registry-based information on variables and the homogeneous study population, for example, the sewing machine operators had similar socioeconomic backgrounds and were all women.

A previous validation study of the questionnaire showed sensitivities of $90 \%$ and $67 \%$ at baseline for the detection of the clinical signs of rotator cuff tendinitis and neck-shoulder pain with pressure tenderness, respectively. In a follow-up examination 1 year later, a similar cross-sectional calculation found the same level of sensitivity, and specificity of $0.68-0.84 .^{22}$ The reliability of the questionnaire was tested by Brauer in 2002, who found that participant recall of pain in the last 3 months was in good to excellent agreement with weekly reporting of pain during the same 3 months. Reproducibility of the questionnaire showed kappa coefficients of $0.44-0.91 .^{3}$

If neck-shoulder pain is fluctuating, the 3-month period of pain used in the questionnaire could be too short to identify those with the most severe and disabling pain. It may have been useful if pain and disorders had been measured several times during the same year.

The relatively large loss to follow-up in 2008 was within our expectations considering the very long follow-up period. There was no difference in neck-shoulder pain and most other characteristics between responders and non-responders, although comorbidity and lower job shoulder exposure seemed to be more prevalent among non-responders, suggesting our selection of patients may have discriminated against participants with other diseases. 
Table 1 Characteristics of the entire study cohort and subgroups: pain groups in 1994, all responders in 2008, pain groups in 2008 and nonresponders in 2008

1994

\begin{tabular}{lll}
$\begin{array}{l}\text { All } \\
\left(n=243^{*}\right)\end{array}$ & $\begin{array}{l}\text { None/mild neck- } \\
\text { shoulder pain } \\
\left(n=156^{*}\right)\end{array}$ & $\begin{array}{l}\text { Moderate/severe } \\
\text { neck-shoulder pain } \\
\left(n=82^{*}\right)\end{array}$ \\
\hline $38.3 \pm 10.4$ & $36.9 \pm 10.6$ & $41.2 \pm 9.5$ \\
$4.5,12,20$ & $5,10,17$ & $6,15,24$ \\
$16.8 \%$ & $<1 \%$ & $47.6 \%$ \\
$(12.3$ to 22.2$)$ & & $(36.4$ to 58.9$)$ \\
$34.7 \%$ & - & -
\end{tabular}

Moderate/severe neck-shoulder $34.7 \%$

pain 1994, proportion $(95 \% \mathrm{Cl}) \quad(28.7$ to 41.1$)$

Comorbidity 1994-2008t,

proportion $(95 \% \mathrm{Cl})$

Job exposure 1994-2008ł,

mean $(95 \% \mathrm{Cl})$

$15.7 \%$

(11.4 to 20.9)

29.3

(27.1 to 31.6$)$

$15,24,36$

Transitions 1994-2008ף,

quartiles

Work status 2008ाף

proportion $(95 \% \mathrm{Cl})$

\begin{tabular}{|c|c|c|c|c|c|c|c|}
\hline Working & $\begin{array}{l}50.4 \% \\
(44.0 \text { to } 56.9)\end{array}$ & $\begin{array}{l}54.5 \% \\
(46.3 \text { to } 62.5)\end{array}$ & $\begin{array}{l}40.2 \% \\
(29.6 \text { to } 51.7)\end{array}$ & $\begin{array}{l}52.3 \% \\
(44.0 \text { to } 60.6)\end{array}$ & $\begin{array}{l}61.8 \% \\
(50.0 \text { to } 72.8)\end{array}$ & $\begin{array}{l}42.5 \% \\
\text { (31.0 to } 54.6)\end{array}$ & $\begin{array}{l}47.3 \% \\
\text { (36.9 to } 57.9 \text { ) }\end{array}$ \\
\hline $\begin{array}{l}\text { Receiving health-related } \\
\text { benefits }\end{array}$ & $\begin{array}{l}20.7 \% \\
(15.7 \text { to } 26.3)\end{array}$ & $\begin{array}{l}15.4 \% \\
(10.1 \text { to } 22.0)\end{array}$ & $\begin{array}{l}31.7 \% \\
(21.9 \text { to } 42.9)\end{array}$ & $\begin{array}{l}20.8 \% \\
(14.6 \text { to } 28.2)\end{array}$ & $\begin{array}{l}6.6 \% \\
(2.2 \text { to } 14.7)\end{array}$ & $\begin{array}{l}35.6 \% \\
\text { (24.7 to } 47.7 \text { ) }\end{array}$ & $\begin{array}{l}20.4 \% \\
(12.8 \text { to } 30.1)\end{array}$ \\
\hline Withdrawn from labour market & $\begin{array}{l}23.6 \% \\
(18.4 \text { to } 29.4)\end{array}$ & $\begin{array}{l}21.8 \% \\
(15.6 \text { to } 29.1)\end{array}$ & $\begin{array}{l}28.0 \% \\
(18.7 \text { to } 39.1)\end{array}$ & $\begin{array}{l}21.5 \% \\
(15.2 \text { to } 28.9)\end{array}$ & $\begin{array}{l}25.0 \% \\
(15.8 \text { to } 36.3)\end{array}$ & $\begin{array}{l}17.8 \% \\
\text { (9.8 to } 28.5)\end{array}$ & $\begin{array}{l}26.9 \% \\
(18.2 \text { to } 37.1)\end{array}$ \\
\hline
\end{tabular}

* Missing information for a few persons in some rows. Number of responders in 2008 refers to those with information on neck-shoulder pain. * ${ }^{*}$ Years as sewing machine operator until 1994. †Proportions of participants who had a Charlson's comorbidity in 1994-2008. ¥The cumulative total shoulder score from job exposure 1994-2008 rated on a 0-10 scale for each year. ๆTransitions between different income types in 1994-2008, from the DREAM registry. ๆףWork status in week number 45 in 2008, from the DREAM registry.

To adjust for comorbidity, data on contacts with hospitals for diseases included in Charlson's Comorbidity Index were used. We did not distinguish between severity and number of contacts, but severity is indirectly taken into account in the index as only the most severe diseases are included. Charlson's Comorbidity Index has been proven to be a useful measure and has prediction validity for events like mortality and disability. ${ }^{35}$ It does not include musculoskeletal diseases, which would also have been inappropriate in the context of this study because they could be related to the outcome.

To investigate whether the number of transitions between different income types had an impact on pain in 2008, we included a variable covering the number of transitions between 1994 and 2008, but it did not effect the results of the multivariate analysis.

The JEM used in this study allowed detailed calculation of job exposures during the entire follow-up period. The total shoulder load was based on expert ratings for each job group in the JEM, which has shown high predictive validity in previous studies and has been validated against direct technical measurements. ${ }^{5} 3132$ Registration of D-ISCO 88 codes for information on jobs is likely superior to self-reported information. Further strengths and limitations of using JEMs have previously been discussed. ${ }^{38}$ In this study we investigated the prognosis for neckshoulder pain, but the JEM only included assessment of shoulder exposure. Exposure of the shoulder could imply exposure of the neck, but an assessment of both neck and shoulder exposure would have been more appropriate.

The analyses on effect modification by job exposure should be interpreted very cautiously as the study was not scaled for subgroup analyses.

\section{Interpretation}

A high prevalence of neck-shoulder pain as well as decreased physical functioning among many of the women was found in 2008, as well as associations between neck-shoulder pain in 1994 and in 2008. This might be due to the persistence of pain and disorders acquired in the job of sewing machine operator at baseline. If so, it suggests that work-related neck-shoulder pain is an extremely long-term complaint. Perhaps an increased propensity to musculoskeletal pain and individual perception and reporting of pain could explain some of the association. The finding of an association with pain 14 years after initial assessment supports the view that longitudinal studies on the course of neck-shoulder pain should include several years of follow-up. ${ }^{3}$

Some $22 \%$ of the women in our study had recovered at follow-up. One study of patients with sick leave due to neck/ shoulder diagnoses found that only $4 \%$ had fully recovered at 12-year follow-up, with $50 \%$ still reporting daily discomfort. ${ }^{13}$ Other studies on the general long-term prognosis for neckshoulder pain have found recovery rates of 36\%-68\% after 5-6 years of follow-up. ${ }^{1012}$ A previous study among sewing machine operators found that $57 \%$ of those who no longer worked in the textile industry had no neck symptoms 6 years after initial assessment; results for shoulder symptoms were similar but not further specified. However, the results from that study may have been affected by selection bias as those unemployed at follow-up were excluded. ${ }^{15}$ Furthermore, comparison between studies on the long-term prognosis of neck-shoulder pain is complicated by differences in populations and outcome measures.

In our study, $40 \%$ of those with available data changed their pain status at least once, while $60 \%$ did not, although we do not know if there were fluctuations at other time points. 
Table 2 Univariate and adjusted ORs from the regression analyses for the following associations: (A) neck-shoulder disorders in 1994 and neckshoulder pain in 2008, (B) neck-shoulder pain in 1994 and neck-shoulder pain in 2008, (C) neck-shoulder disorders in 1994 and physical functioning in 2008, and (D) neck-shoulder pain in 1994 and physical functioning in 2008

\begin{tabular}{|c|c|c|c|c|c|}
\hline \multirow[b]{2}{*}{ Variables } & \multirow[b]{2}{*}{ Categories } & \multicolumn{2}{|c|}{ Univariate } & \multicolumn{2}{|c|}{ Multivariate* } \\
\hline & & OR & $95 \% \mathrm{Cl}$ & OR & $95 \% \mathrm{Cl}$ \\
\hline \multicolumn{6}{|c|}{ Moderate/severe neck-shoulder pain 2008} \\
\hline \multicolumn{6}{|l|}{ A } \\
\hline \multirow[t]{2}{*}{ Neck-shoulder disorder 1994} & Absence, $n=124$ & 1 & Ref. & 1 & Ref. \\
\hline & Presence, $n=23$ & 4.8 & 1.7 to 13.8 & 5.9 & 1.9 to 17.7 \\
\hline \multirow[t]{2}{*}{ Comorbidity 1994-2008 } & No comorbidity, $n=130$ & 1 & Ref. & 1 & Ref. \\
\hline & $\geq 1$ comorbidity, $n=17$ & 2.1 & 0.7 to 5.9 & 3.5 & 1.0 to 11.4 \\
\hline \multicolumn{2}{|l|}{ Age, squared } & 0.9 & 0.9 to 1.0 & 0.9 & 0.9 to 1.0 \\
\hline \multirow{3}{*}{$\begin{array}{l}\text { Number of transitions between } \\
\text { income types 1994-2008 }\end{array}$} & 0 to $\leq 17$ transitions, $n=46$ & 1 & Ref. & 1 & Ref. \\
\hline & $>17$ to $\leq 31$ transitions, $n=46$ & 1.2 & 0.5 to 2.8 & 1.4 & 0.6 to 3.4 \\
\hline & $>31$ transitions, $n=55$ & 0.8 & 0.3 to 1.6 & 0.7 & 0.3 to 1.6 \\
\hline \multicolumn{6}{|l|}{ B } \\
\hline \multirow{2}{*}{ Neck-shoulder pain 1994} & None/mild pain, $\mathrm{n}=98$ & 1 & Ref. & 1 & Ref. \\
\hline & Moderate/severe pain, $n=50$ & 7.0 & 3.2 to 15.4 & 8.2 & 3.5 to 19.2 \\
\hline \multirow[t]{2}{*}{ Comorbidity 1994-2008 } & No comorbidity, $n=131$ & 1 & Ref. & 1 & Ref. \\
\hline & $\geq 1$ comorbidity, $n=17$ & 2.1 & 0.7 to 5.9 & 3.2 & 0.9 to 11.4 \\
\hline \multicolumn{2}{|l|}{ Age, squared } & 0.9 & 0.9 to 1.0 & 0.9 & 0.9 to 1.0 \\
\hline \multirow{3}{*}{$\begin{array}{l}\text { Number of transitions between } \\
\text { income types 1994-2008 }\end{array}$} & 0 to $\leq 17$ transitions, $\mathrm{n}=46$ & 1 & Ref. & 1 & Ref. \\
\hline & $>17$ to $\leq 31$ transitions, $n=46$ & 1.2 & 0.5 to 2.8 & 1.1 & 0.5 to 2.9 \\
\hline & $>31$ transitions, $n=56$ & 0.8 & 0.3 to 1.6 & 0.7 & 0.3 to 1.6 \\
\hline \multicolumn{6}{|l|}{ Low physical functioning 2008} \\
\hline \multicolumn{6}{|l|}{ C } \\
\hline \multirow[t]{2}{*}{ Neck-shoulder disorder 1994} & Absence, $n=132$ & 1 & Ref. & 1 & Ref. \\
\hline & Presence, $n=23$ & 5.5 & 1.8 to 17.1 & 5.0 & 1.5 to 16.1 \\
\hline \multirow[t]{2}{*}{ Comorbidity 1994-2008 } & No comorbidity, $n=134$ & 1 & Ref. & 1 & Ref. \\
\hline & $\geq 1$ comorbidity, $n=21$ & 7.1 & 2.0 to 25.1 & 4.6 & 1.2 to 17.1 \\
\hline \multicolumn{2}{|l|}{ Age, squared } & 1.0 & 1.0 to 1.0 & 1.0 & 1.0 to 1.0 \\
\hline \multirow{3}{*}{$\begin{array}{l}\text { Number of transitions between } \\
\text { income types 1994-2008 }\end{array}$} & 0 to $\leq 17$ transitions, $n=49$ & 1 & Ref. & 1 & Ref. \\
\hline & $>17$ to $\leq 31$ transitions, $n=49$ & 0.9 & 0.4 to 2.0 & 1.2 & 0.5 to 3.0 \\
\hline & $>31$ transitions, $n=57$ & 1.7 & 0.8 to 3.7 & 2.4 & 1.0 to 5.9 \\
\hline \multicolumn{6}{|l|}{ D } \\
\hline \multirow[t]{2}{*}{ Neck-shoulder pain 1994} & None/mild pain, $n=103$ & 1 & Ref. & 1 & Ref. \\
\hline & Moderate/severe pain, $n=53$ & 2.5 & 1.3 to 5.0 & 2.2 & 1.1 to 4.6 \\
\hline \multirow[t]{2}{*}{ Comorbidity 1994-2008 } & No comorbidity, $n=135$ & 1 & Ref. & 1 & Ref. \\
\hline & $\geq 1$ comorbidity, $n=21$ & 7.1 & 2.0 to 25.1 & 4.5 & 1.2 to 16.6 \\
\hline \multicolumn{2}{|l|}{ Age, squared } & 1.0 & 1.0 to 1.0 & 1.0 & 1.0 to 1.0 \\
\hline \multirow{3}{*}{$\begin{array}{l}\text { Number of transitions between } \\
\text { income types 1994-2008 }\end{array}$} & 0 to $\leq 17$ transitions, $n=49$ & 1 & Ref. & 1 & Ref. \\
\hline & $>17$ to $\leq 31$ transitions, $n=49$ & 0.5 & 0.1 to 1.8 & 1.0 & 0.4 to 2.5 \\
\hline & $>31$ transitions, $n=58$ & 0.7 & 0.2 to 2.2 & 2.1 & 0.9 to 4.9 \\
\hline
\end{tabular}

${ }^{*}$ Adjusted for age squared, comorbidity 1994-2008 and number of transitions between different income types 1994-2008.

Neck-shoulder pain has previously been described as fluctuating ${ }^{36}$ as seen in $40 \%$ of our participants, while $60 \%$ seemed to have a more stable condition. If fluctuation is a characteristic of neck-shoulder pain, this will be of importance in research on prognosis as well as in clinical practice.

The more specific definition of neck-shoulder disorders based on clinical examination and self-reported pain did not show a stronger association with neck-shoulder pain or physical functioning at follow-up than neck-shoulder pain based only on self-reported pain. This suggests that the broader definition of neck-shoulder disorders did not improve pain prediction, which is in line with previous findings. ${ }^{39}$

There were also significant associations between other anatomical regions and pain in 1994 and in 2008. The OR for the right shoulder seemed to be higher than for the left shoulder, but there was no difference between the neck and the shoulders.

The mean cumulative job exposure during the 14 years from 1994 to 2008 was 29.3 points with a range of $0-84.7$ points. The mean job exposure was therefore lower than if the women had continued as sewing machine operators during the entire follow-up period, which would have been 35.8 points. However, a fraction of the women had higher exposure than if they had continued in the textile industry, as they were employed, for example, in laundry work, slaughter house work and other industrial jobs. A more detailed description of their work participation is available in another article. ${ }^{20}$

We used the JEM on occupational shoulder exposure to examine if exposure to mechanical risk factors changed the 
Table 3 Analysis for effect modification by cumulative job exposure on the associations between neck-shoulder pain in 1994 and neck-shoulder pain/physical functioning in 2008

\begin{tabular}{|c|c|c|c|c|c|}
\hline \multirow[b]{2}{*}{ Variables } & \multirow[b]{2}{*}{ Categories } & \multicolumn{2}{|c|}{ Low job exposure* } & \multicolumn{2}{|c|}{ High job exposure* } \\
\hline & & OR & $95 \% \mathrm{Cl}$ & OR & $95 \% \mathrm{Cl}$ \\
\hline \multicolumn{2}{|c|}{ Moderate/severe neck-shoulder pain 2008} & $\mathrm{n}=75$ & & $\mathrm{n}=72$ & \\
\hline \multirow[t]{2}{*}{ Neck-shoulder pain 1994} & None/mild pain & 1 & Ref. & 1 & Ref. \\
\hline & Moderate/severe pain & 12.0 & 3.2 to 44.4 & 9.1 & 2.4 to 34.0 \\
\hline \multicolumn{2}{|l|}{ Low physical functioning 2008} & $\mathrm{n}=80$ & & $\mathrm{n}=72$ & \\
\hline \multirow[t]{2}{*}{ Neck-shoulder pain 1994} & None/mild pain & 1 & Ref. & 1 & Ref. \\
\hline & Moderate/severe pain & 2.2 & 0.7 to 6.4 & 1.9 & 0.6 to 5.8 \\
\hline \multicolumn{6}{|c|}{ Analysis for effect modification only on those still working in $2008(n=74)$} \\
\hline \multicolumn{2}{|c|}{ Moderate/severe neck-shoulder pain 2008} & $n=24$ & & $\mathrm{n}=50$ & \\
\hline \multirow[t]{2}{*}{ Neck-shoulder pain 1994} & None/mild pain & 1 & Ref. & 1 & Ref. \\
\hline & Moderate/severe pain & 11.5 & 0.6 to 217.6 & 20.8 & 3.5 to 122.8 \\
\hline \multicolumn{2}{|l|}{ Low physical functioning 2008} & $n=24$ & & $\mathrm{n}=48$ & \\
\hline \multirow[t]{2}{*}{ Neck-shoulder pain 1994} & None/mild pain & 1 & Ref. & 1 & Ref. \\
\hline & Moderate/severe pain & 1.5 & 0.2 to 13.0 & 1.5 & 0.4 to 6.4 \\
\hline
\end{tabular}

The lower part of the table presents this analysis for the subgroup still working in 2008.

*Adjusted for age squared, comorbidity 1994-2008 and number of transitions between different income types 1994-2008.

prognosis for neck-shoulder pain, thereby allowing it to be modified. The results of the analysis on effect modification of job exposure revealed no significant differences between those with high versus low cumulative job exposure. For the group with low job exposure, the OR for the association between pain in 1994 and pain in 2008 was slightly higher than for the group with high exposure. However, the highest OR was seen in the group with high exposure when those who had stopped working before 2008 were excluded from subanalysis on the assumption that individuals with the worst prognosis had stopped working ${ }^{20}$ and would therefore not have accumulated much job exposure. Our interpretation of these results, remembering the very high insecurity of the estimates, was that high job exposure could worsen the prognosis for neck-shoulder pain in the group who were still working.

\section{Generalisability}

Our results are generalisable to groups of female workers who have been exposed to risk factors for neck-shoulder pain in former jobs, such as slaughter house workers, cleaners, postal workers and nurses' aides. ${ }^{31}$

Patients with musculoskeletal complaints consulting occupational physicians are often advised to continue to work despite their pain, even though they may be exposed to risk factors. ${ }^{40}$ The women in this study were forced to stop working in the textile companies, but this did not result in cessation of their neck-shoulder pain. However, shoulder exposures in later jobs may have worsened the prognosis for some of the women.

The results call for attention to be given to the long-term prognosis of neck-shoulder pain and for methods to prevent the development of chronic pain. This long-term prognosis for neck-shoulder pain should be considered when devising rehabilitation programmes and delivering suitable advice for this group of patients and workers. There are various rehabilitation possibilities, including adjustment of ergonomics at the workplace, transferal to alternative duties, and exercises, ${ }^{40}$ but the intervention strategy should be based on research concerning effect on the long-term outcome and have a long-term perspective.

Acknowledgements We would like to thank Jesper Medom Vestergaard, Department of Occupational Medicine, Central Region, Denmark, for assisting with data management. Furthermore, we thank the group who developed the job exposure matrix for permission to use it.

Contributors AK and JHA were responsible for collection of baseline data. The study was mainly performed by ELTJ. AD introduced for the job exposure matrix. All authors revised and approved the manuscript.

Funding This study was funded by The Danish Working Environment Research Fund, (project no. 02-2015-09 20150067117).

Competing interests None declared.

Ethics approval The study was approved by Danish Data Protection Agency (j. no. 2007-58-0010). All data were collected before the present study was initiated, and studies based on register information do not need approval from the Committee System on Biomedical Research Ethics in Denmark.

Provenance and peer review Not commissioned; externally peer reviewed.

(C) Article author(s) (or their employer(s) unless otherwise stated in the text of the article) 2018. All rights reserved. No commercial use is permitted unless otherwise expressly granted.

\section{REFERENCES}

1 Miranda H, Viikari-Juntura E, Heistaro S, et al. A population study on differences in the determinants of a specific shoulder disorder versus nonspecific shoulder pain without clinical findings. Am J Epidemio/ 2005;161:847-55.

2 Jacobsson L, Lindgärde F, Manthorpe R. The commonest rheumatic complaints of over six weeks' duration in a twelve-month period in a defined Swedish population. Prevalences and relationships. Scand J Rheumatol 1989;18:353-60.

3 Luime JJ, Koes BW, Miedem HS, et al. High incidence and recurrence of shoulder and neck pain in nursing home employees was demonstrated during a 2-year follow-up. J Clin Epidemio/ 2005:58:407-13.

4 Andersen $\mathrm{JH}$, Kaergaard A, Frost P, et al. Physical, psychosocial, and individual risk factors for neck/shoulder pain with pressure tenderness in the muscles among workers performing monotonous, repetitive work. Spine 2002;27:660-7.

5 Dalbøge A, Frost P, Andersen JH, et al. Cumulative occupational shoulder exposures and surgery for subacromial impingement syndrome: a nationwide Danish cohort study. Occup Environ Med 2014;71:750-6.

6 Kaergaard A, Andersen JH. Musculoskeletal disorders of the neck and shoulders in female sewing machine operators: prevalence, incidence, and prognosis. Occup Environ Med 2000;57:528-34.

7 Struyf F, Geraets J, Noten S, et al. A multivariable prediction model for the chronification of non-traumatic shoulder pain: a systematic review. Pain Physician 2016;19:1-10

8 Bruls VE, Bastiaenen $\mathrm{CH}$, de Bie RA. Prognostic factors of complaints of arm, neck, and/ or shoulder: a systematic review of prospective cohort studies. Pain 2015;156:765-88.

9 van der Windt DA, Koes BW, Boeke AJ, et al. Shoulder disorders in general practice: prognostic indicators of outcome. Br J Gen Pract 1996;46:519-23.

10 Cassou B, Derriennic F, Monfort C, et al. Chronic neck and shoulder pain, age, and working conditions: longitudinal results from a large random sample in France. Occup Environ Med 2002;59:537-44 
11 Grooten WJ, Mulder M, Josephson M, et al. The influence of work-related exposures on the prognosis of neck/shoulder pain. Eur Spine J 2007;16:2083-91.

12 Gill TK, Shanahan EM, Taylor AW, et al. Shoulder pain in the community: an examination of associative factors using a longitudinal cohort study. Arthritis Care Res 2013;65:2000-7.

13 Kjellman G, Oberg B, Hensing G, et al. A 12-year follow-up of subjects initially sicklisted with neck/shoulder or low back diagnoses. Physiother Res Int 2001;6:52-63.

14 Christensen JO, Knardahl S. Time-course of occupational psychological and social factors as predictors of new-onset and persistent neck pain: a three-wave prospective study over 4 years. Pain 2014;155:1262-71.

15 Schibye B, Skov T, Ekner D, et al. Musculoskeletal symptoms among sewing machine operators. Scand J Work Environ Health 1995;21:427-34.

16 van der Heijden GJMG. Shoulder disorders: a state-of-the-art review. Best Pract Res Clin Rheumatol 1999:13:287-309.

17 Hush JM, Lin CC, Michaleff ZA, et al. Prognosis of acute idiopathic neck pain is poor: a systematic review and meta-analysis. Arch Phys Med Rehabil 2011;92:824-9.

18 Engebretsen K, Grotle M, Bautz-Holter E, et al. Predictors of Shoulder Pain and Disability Index (SPADI) and work status after 1 year in patients with subacromial shoulder pain. BMC Musculoskelet Disord 2010;11:218

19 Virtanen P, Janlert U, Hammarström A. Health status and health behaviour as predictors of the occurrence of unemployment and prolonged unemployment. Public Health 2013;127:46-52.

20 Jakobsen EL, Biering K, Kærgaard A, et al. Neck-shoulder pain and work status among former sewing machine operators: a 14-year follow-up study. J Occup Rehabil 2017 (Epub ahead of print).

21 Kooijman MK, Barten DJ, Swinkels IC, et al. Pain intensity, neck pain and longer duration of complaints predict poorer outcome in patients with shoulder pain-a systematic review. BMC Musculoskelet Disord 2015;16:288.

22 Kaergaard A, Andersen JH, Rasmussen K, et al. Identification of neck-shoulder disorders in a 1 year follow-up study. Validation of a questionnaire-based method. Pain 2000;86:305-10.

23 Andersen JH, Kaergaard A, Mikkelsen S, et al. Risk factors in the onset of neck/ shoulder pain in a prospective study of workers in industrial and service companies. Occup Environ Med 2003;60:649-54.

24 Frost $\mathrm{P}$, Bonde JP, Mikkelsen $\mathrm{S}$, et al. Risk of shoulder tendinitis in relation to shoulder loads in monotonous repetitive work. Am J Ind Med 2002:41:11-18.

25 Bonde JP, et al. Prognosis of shoulder tendonitis in repetitive work: a follow up study in a cohort of Danish industrial and service workers. Occup Environ Med 2003;60:8e-8.
26 Von Korff M, Ormel J, Keefe FJ, et al. Grading the severity of chronic pain. Pain 1992;50:133-49.

27 Hawkins RJ, Kennedy JC. Impingement syndrome in athletes. Am J Sports Med 1980;8:151-8.

28 Rand Health. 36-Item Short Form Survey (SF-36) Scoring Instructions. http://www. rand.org/health/surveys_tools/mos/36-item-short-form/scoring.html (accessed 1 Feb 2017).

29 Charlson ME, Pompei P, Ales KL, et al. A new method of classifying prognostic comorbidity in longitudinal studies: development and validation. J Chronic Dis 1987;40:373-83.

30 Lynge E, Sandegaard JL, Rebolj M. The Danish National Patient Register. Scand J Public Health 2011;39:30-3.

31 Svendsen SW, Dalbøge A, Andersen JH, et al. Risk of surgery for subacromial impingement syndrome in relation to neck-shoulder complaints and occupational biomechanical exposures: a longitudinal study. Scand I Work Environ Health 2013;39:568-77.

32 Dalbøge $A$, Hansson $G \AA$, Frost $P$, et al. Upper arm elevation and repetitive shoulder movements: a general population job exposure matrix based on expert ratings and technical measurements. Occup Environ Med 2016;73:553-60.

33 Hjollund NH, Larsen FB, Andersen JH. Register-based follow-up of social benefits and other transfer payments: accuracy and degree of completeness in a Danish interdepartmental administrative database compared with a population-based survey. Scand J Soc Med 2007;35:497-502.

34 Schmidt M, Pedersen L, Sørensen HT. The Danish civil registration system as a tool in epidemiology. Eur J Epidemiol 2014;29:541-9.

35 Roffman CE, Buchanan J, Allison GT, et al. Charlson Comorbidities Index. J Physiother 2016;62:171.

36 Hoy D, March L, Woolf A, et al. The global burden of neck pain: estimates from the global burden of disease 2010 study. Ann Rheum Dis 2014;73:1309-15.

37 Brauer C, Thomsen JF, Loft IP, et al. Can we rely on retrospective pain assessments? Am J Epidemiol 2003;157:552-7.

38 Olsen J. Limitations in the use of job exposure matrices. Scand J Soc Med 1988;16:205-8.

39 Palmer KT, Harris EC, Linaker C, et al. Optimal case definitions of upper extremity disorder for use in the clinical treatment and referral of patients. Arthritis Care Res 2012:64:573-80.

40 Waddell G, Burton AK. Concepts of rehabilitation for the management of common health problems. Norwich: The Stationery Office, 2004. 